\title{
The importance of combating malnutrition in care
}

\author{
Omorogieva Ojo \\ Senior Lecturer in Primary Care Faculty of Education and Health, University of Greenwich
}

Malnutrition results from a deficiency of macronutrients (energy and protein) and micronutrients (vitamins and minerals), that may impact on body composition, function and/or clinical outcomes (National Institute for Health and Care Excellence, 2006). A range of factors, including impaired food intake (seen in individuals who are anorexic or have difficulties swallowing), increased nutrient requirements (seen during infection) and/or loss of nutrients which may be present in individuals with inflammatory bowel disease, have been known to cause malnutrition (Dunne, 2009).

\section{The cost of malnutrition}

Malnutrition has a significant cost in terms of its impact on morbidity and mortality. In addition, malnutrition places an enormous financial burden on the NHS, due to its effect on wound healing, skin integrity and length of hospital stay. It has also been recognised that malnutrition is potentially a reversible risk factor for pressure ulcers and other conditions (Meijers et al, 2010). Therefore, putting measures in place, such as early identification of those at risk of malnutrition through screening and developing strategies for enhanced feeding programmes, will promote the nutritional status and clinical outcomes of residents.

According to Merrell et al (2012), approximately 32\% of people aged 65 years and over, and $23 \%$ of those below 65 years of age in the UK are malnourished. A further estimated 7 million people in the UK are at risk of malnutrition, costing about $£ 13$ billion per year (Merrell et al, 2012). Many of those at risk of malnutrition are in hospitals (estimated at 150000 people), care homes (approximiately 600000 ) and sheltered accommodation (around 700000 ), while around 6 million people living in the community are dependent on others for their nutritional requirements (Merrell et al, 2012).

Malnutrition may predispose individuals to poor health outcomes including fall rates, diseases, delayed recovery and increased hospitalisation (Neyens et al, 2010; Palm et al, 2010). Therefore, the prevention of malnutrition and these poor health outcomes should be seen as crucial patient safety issues (Neyens et al, 2010). Merrell et al (2012), observed that while malnutrition in hospitals has been well documented, there appears to be a lack of commensurate effort with respect to research into malnutrition in care homes, despite the high number of those at risk of malnutrition living in these settings.

\section{Types of malnutrition in the care home}

There are different types of malnutrition which can be found in the care home with a range of clinical manifestations, including skin and hair changes, and weight loss. While some residents may present with energy deficiency, protein deficiency or protein-energy malnutrition, other types of malnutrition may manifest in the form of micronutrient deficiencies (such as minerals and/or vitamins deficiencies). There could also be a combination of these nutritional deficiencies.

'A further estimated 7 million people are at risk of malnutrition, costing about $£ 13$ billion per year' 
However, care home residents with malnutrition may be classified based on the use of the malnutrition universal screening tool (MUST) score. A score of 0 would show a low risk of malnutrition; medium risk would be a score of 1 , while a high risk would be a score of 2 or more (Brotherton et al, 2012).

\section{The impact of malnutrition}

There is evidence that the results of malnutrition, such as undesired weight loss, a body mass index (BMI) of $<18.5$, and low nutritional intake, are related to pressure ulcers and other clinical outcomes (Meijers et al, 2010) (Table 1). In a study by Neyens et al (2010), it was observed that malnutrition was significantly related to falls rate. Other effects of malnutrition may include its impact on physical status, psychological wellbeing, response to treatment and quality of life of care home residents (Dunne, 2009). A study by Muurinen et al (2015) found that there was a significant relationship between the nutritional status and care of residents with dementia and their psychological wellbeing.

Table 1. The impact on malnutrition on residents

\begin{tabular}{|l|l|}
\hline Table 1. The impact on mainutrition on residents \\
\hline Physical, physiological and psychosocial changes & Explanation \\
\hline Impaired immune response & Results from poor nutritional intake and it increases the risk of infection \\
\hline Reduced muscle strength & Results from poor nutritional intake and impairs mobility \\
\hline Impaiced wound healing and pressure ulcers & Results from poor nutritional intake and reduced moblity \\
\hline Impaiced psychological function & Results from poor nutritional intake \\
\hline Water and electrolytes disturbances & Results from malnutrition \\
\hline Impaiced thermocegulation & Results from malnutrition \\
\hline Source: Dunne, $2009 ;$ Brotherton et at 2012 & \\
\hline
\end{tabular}

\section{Strategies for combating malnutrition in the care home}

A number of measures have been shown to be effective in reducing the risk of malnutrition. These measures include screening of care home residents on admission and when clinical concerns are evident (Merrell et al, 2012) - it has been stated that the use of MUST may be useful in determining those at risk of malnutrition. The process often includes taking the height and weight of the individuals (in order to establish their BMI), evaluating the percentage of unintentional weight loss, and the risk of future impaired nutrient intake (Merrell et al, 2012). Another tool that has been developed specifically for use with older people is the mini-nutritional assessment (MNA); it is aimed at those at risk of malnutrition who may benefit from early intervention (Soini et al, 2004). The MNA consists of four parts: anthropometric measurements, general status, diet information and a subjective assessment (Soini et al, 2004).

Other measures that could be employed to tackle malnutrition in care may involve: the use of nutritional interventions, good oral health, training and sustenance of national standards for food provisions, a good meal environment, availability of meal choices and provision of support with eating - especially for residents with a disability (Woo et al, 2005; Brown and Copeman, 2008). The use of food enhancers and oral nutritional supplements (ONS) as part of nutritional interventions may promote food intake, reduce the risk of malnutrition and decrease the rates of falls (Woo et al, 2005; Neyens et al, 2010). These nutritional interventions may also be in the form of energy and protein rich diets and energy-enriched snacks, which are often provided between meals (Dunne, 2009; Neyens et al, 2010).

'A number of measures have been shown to be effective in reducing the risk of malnutrition' 
In particular, ONS are enriched nutritional products in the form of multinutrient liquid, semisolid or powder products; they provide macronutrients and micronutrients, which are used to support individuals with nutritional deficits or individuals at risk of developing malnutrition such as residents with swallowing difficulties or Alzheimer's disease (Holdoway, 2012; Ojo, 2016). There is a wide range of ONS on the market in the UK (Table 2). However, the most common are those rich in energy, proteins, minerals and vitamins (Ojo, 2016). It is clear that these products are often used as supplements, rather than the primary source of nutrition, except in patients on bolus tube feeding and/or those on a liquid diet (Holdoway, 2012). A range of factors, including nutritional status, disease condition, policies and patient preference may guide the choice of ONS.

Table 2. The benefits of different types of oral nutritional supplements (ONS)

\begin{tabular}{|c|c|c|}
\hline Type & Comments & Benefits \\
\hline High protein diet & $\begin{array}{l}\text { Available as jellex, shots and milkshakes. The protein } \\
\text { may range from } 11-20 \mathrm{~g} \text {, in volumes of } 30-220 \mathrm{ml}\end{array}$ & $\begin{array}{l}\text { Suitable for wound healing, post-operative patients, } \\
\text { older people and certain cancers }\end{array}$ \\
\hline Flbse containing ONS & - & Suitable tor individuals who are constipated \\
\hline Pre-thickened ONS & $\begin{array}{l}\text { Available in the form of thickened liquids and smooth } \\
\text { pudding styles. The energy density may range from } \\
\text { approximately } 1.4-2.5 \text { kcal/ml }\end{array}$ & Useful for individuals with swallowing difficulty \\
\hline $\begin{array}{l}\text { Small volume, high: } \\
\text { energy-density ONS }\end{array}$ & - & $\begin{array}{l}\text { Sultable for patients who cannot consume large } \\
\text { volumes }\end{array}$ \\
\hline Juice type & $\begin{array}{l}\text { The energy density may range from } 1.25-1.5 \mathrm{kcal} / \mathrm{mL} \text { in } \\
\text { volumes of } 200-220 \mathrm{ml}\end{array}$ & May be useful for those who do not like milky drinks \\
\hline Milkshake type & $\begin{array}{l}\text { The energy density may cange from } 1-2.4 \mathrm{kcal} / \mathrm{ml} \text { in } \\
\text { volumes of } 125-220 \mathrm{ml}\end{array}$ & Enhances individual choices \\
\hline Soup type & $\begin{array}{l}\text { The total volume may range from } 200-330 \mathrm{ml} \text { and may } \\
\text { be in the form of ready mix or powder (to be miked with } \\
\text { water or milid, with an eneegy density of } 1-1.5 \mathrm{kcal} / \mathrm{ml}\end{array}$ & Enhances individual choices \\
\hline
\end{tabular}

\section{Conclusion}

Despite the efforts aimed at combating malnutrition in care, there are challenges facing the sector, including inadequate staffing levels and a dearth of organised framework for nutritional provisions (Brown and Copeman, 2008). The prevalence of malnutrition in the care home is significant, and its impact on the physical health and psychological wellbeing of residents may be profound. Although a range of strategies are available to combat malnutrition, including the use of ONS, challenges remain.

\section{References}

1. British Association for Parenteral and Enteral Nutrition (2016) Oral Nutritional Supplements. http://bit.ly/2dxHJZD (accessed 3 October 2016)

2. Brotherton A, Holdoway A, Mason $P$ et al (2012) Managing adult malnutrition in the community Including a pathway for the appropriate use of oral nutritional supplements. http://bit.ly/1S8uadT (accessed 3 October 2016)

3. Brown L, Copeman J (2008) Nutritional care in care homes: experiences and attitudes of care home staff. J Human Nutr Dietetics 21(3): 282-3

4. Dunne A (2009) Malnutrition in care homes: improving nutritional status. Nursing \& Residential Care 11(9): 437-42. doi: 10.12968/nrec.2009.11.9.43726 Link 
5. Holdoway A (2012) Managing disease-related malnutrition in the community. Br J Community Nurs 17(Suppl 11): S12-8. doi: 10.12968/bjcn.2012.17.Sup11.S12 Link

6. Meijers J, Shahin E, Tannen A et al (2010) The relationship between malnutrition parameters and pressure ulcers in care. J Clin Nurs 19(Suppl 1): 154

7. Merrell J, Philpin S, Warring J et al (2012) Addressing the nutritional needs of older people in residential care homes. Health Soc Care Community 20(2): 208-15. doi: 10.1111/j.1365-2524.2011.01033.x

8. Muurinen S, Savikko N, Soini H et al (2015) Nutrition and psychological well-being among long-term care residents with dementia. J Nutr Health Aging 19(2): 178-82. doi: 10.1007/s12603-014-0519-z

9. National Institute for Health and Care Excellence (2006) Nutrition Support for Adults: Oral Nutrition Support, Enteral Tube Feeding and Parenteral Nutrition. http://bit.ly/2aMUn6k (accessed 3 October 2016)

10. Neyens J, Halfens R, Spreeuwenberg et al (2010) Relationships between malnutrition and falls in elderly patients in Dutch care homes. J Clin Nurs 19(Suppl 1): 154-5

11. Ojo O (2016) Managing malnutrition for older people in residential care. Nursing \& Residential Care 18(9): 470-5. doi: 10.12968/nrec.2016.18.9.470 Link

12. Palm R, Reuther S, Mayer $\mathrm{H}$ et al (2010) Factors associated with malnutrition in German nursing home residents. J Clin Nurs 19(Suppl 1): 155

13. Soini $H$, Routasalo $P$, Lagström $H$ (2004) Characteristics of the mini-nutritional assessment in elderly home-care patients. Eur J Clin Nutr 58(1): 64-70

14. Woo J Chi I, Hui E et al (2005) Low staffing level is associated with malnutrition in long-term residential care homes. Eur J Clin Nutr 59(4): 474-9 